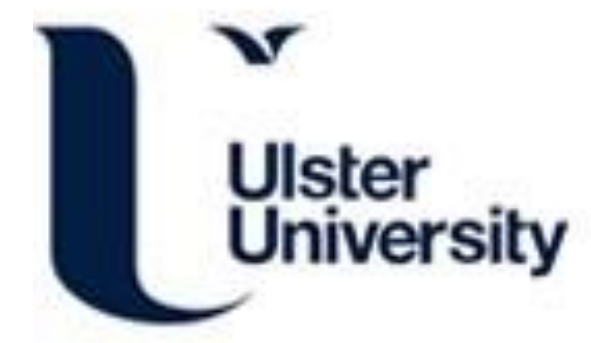

\title{
Analyses of the mechanical, electrical and electromagnetic shielding properties of thermoplastic composites doped with conductive nanofillers
}

Yilmaz, A. C., Ozen, M. S., Sancak, E., Erdem, R., Erdem, O., \& Soin, N. (2018). Analyses of the mechanical, electrical and electromagnetic shielding properties of thermoplastic composites doped with conductive nanofillers. Journal of Composite Materials, 52(11), 1423-1432. https://doi.org/10.1177/0021998317752503

Link to publication record in Ulster University Research Portal

Published in:

Journal of Composite Materials

Publication Status:

Published (in print/issue): 01/05/2018

DOI:

$10.1177 / 0021998317752503$

Document Version

Author Accepted version

\section{General rights}

Copyright for the publications made accessible via Ulster University's Research Portal is retained by the author(s) and / or other copyright owners and it is a condition of accessing these publications that users recognise and abide by the legal requirements associated with these rights.

\section{Take down policy}

The Research Portal is Ulster University's institutional repository that provides access to Ulster's research outputs. Every effort has been made to ensure that content in the Research Portal does not infringe any person's rights, or applicable UK laws. If you discover content in the Research Portal that you believe breaches copyright or violates any law, please contact pure-support@ulster.ac.uk. 


\title{
Analyses of the Mechanical, Electrical and Electromagnetic Shielding Properties of Thermoplastic Composites Doped with Conductive Nanofillers
}

\author{
*Ali Can Yilmaz ${ }^{\mathrm{a}}$, Mustafa Sabri Ozen ${ }^{\mathrm{b}}$, Erhan Sancak ${ }^{\mathrm{b}}$, Ramazan Erdem ${ }^{\mathrm{c}}$, Ozlem Erdem ${ }^{\mathrm{d}}$, \\ Navneet Soin ${ }^{\mathrm{e}}$ \\ ${ }^{a}$ Department of Motor Vehicles and Transportation Technologies, Adana Vocational School of Higher \\ Education, Cukurova University, 01330, Adana, Turkey \\ ${ }^{b}$ Department of Textile Engineering, Technology Faculty, Marmara University, 34365, Istanbul, Turkey \\ ${ }^{c}$ Department of Textile Technologies, Serik G-S. Sural Vocational School of Higher Education, Akdeniz \\ University, 07058, Antalya, Turkey \\ ${ }^{d}$ Department of Textile Technologies, Adana Vocational School of Higher Education, Cukurova University, \\ 01330, Adana, Turkey \\ ${ }^{e}$ Institute for Materials Research and Innovation (IMRI), University of Bolton, Bolton, UK
}

\begin{abstract}
The purpose of this study is to observe effect of incorporating vapor grown carbon nanofibers with various amounts in polyvinylidene fluoride matrix in terms of mechanical strength and electromagnetic shielding effectiveness. Thermoplastic conductive nanocomposites were prepared by heat pressed compression molding. Vapor grown carbon nanofibers were utilized at various weight ratios (1 wt. \%, 3 wt. \%, 5 wt. \% and 8 wt. \%) as conductive and reinforcing materials. Polyvinylidene fluoride was used as a thermoplastic polymer matrix. SEM analysis was conducted in order to characterize the morphology and structural properties of the nanocomposites and results revealed well dispersion of carbon nanofibers within the matrix for all concentrations. Mechanical characteristics were investigated according to standards. Findings proved that overall increments of $16 \%, 37,5 \%$ and 56\% were achieved in terms of tensile strength, elasticity modulus and impact energy,

*: Corresponding author

E-mail: acyilmaz@cu.edu.tr
\end{abstract}


respectively where a total reduction of $44.8 \%$ was observed in terms of elongation for 8 wt.\% vapor grown nanofiber matrix compared to that of 0 wt.\%. Electromagnetic shielding effectivenesses of the nanocomposites were determined by standard protocol using coaxial transmission line measurement technique in the frequency range of 15-3000 MHz. It was observed that resistance, sheet resistance and resistivity of nanocomposites depicted substantial reduction with the increment of nanofiber content. Nevertheless, it was observed that nanofiber content, dispersion and network formation within the composites were highly influent on the electromagnetic shielding effectiveness performance of the structures.

Keywords: Carbon Nanofiber, Electromagnetic Shielding Effectiveness, Polymer Composites, Mechanical Properties

\section{Introduction}

Recently, there has been a tremendous effort spent on developing nanofiber/polymer composites for variety of industrial applications. One of the biggest reasons for these great attempts is the desire to obtain more functional and efficient materials compared to traditional microfiber/polymer composites. Inorganic fibers (glass and carbon fibers) and aromatic organic fibers (Aramid) are the traditional fillers used to increase the performance characteristics of polymers. On the other hand, it has already been reported that as the fiber diameter decreases, higher reinforcing capabilities are gained due to decrease in number of defects, increase in the contact area between filler and polymer matrix, and also increment in the fiber flexibility resulting better bending property without breaking [1]. Therefore, utilizing nanofibers as filler materials for polymer composite production has been widely investigated [2].

\footnotetext{
*: Corresponding author
}

E-mail: acyilmaz@cu.edu.tr 
Concerns about electromagnetic interference (EMI) have been growing among the researchers due to their potential health hazards on living creatures and their negative impacts on the performance of the electronic devices, as the usage of electrical and electronic equipment have been accumulating day by day [3]. The source of the EMI is principally electrical with unwanted electromagnetic emission being radiated or conducted [4]. Electromagnetic shielding effectiveness (EMSE) is described as blocking the electromagnetic fields by facilitating conductive or magnetic materials as barriers [5]. Effectiveness of a shield is influenced by the frequency of the EM, the distance of the shield from the source, the thickness of the shield and the shielding material composition. EMSE is calculated by (1) and evaluated in decibels $(\mathrm{dB})$;

$S E=10 \lg \frac{P o}{P t}=20 \lg \frac{E o}{E t} 20 \lg \frac{H o}{H t}$

where $P_{0}, E_{0}$ and $H_{0}$ are the power, the electric and the magnetic field intensities pertain to the shield, respectively and $P_{t}, E_{t}$ and $H_{t}$ are the factors transmitted through the shield [6]. Accordingly, some of the grades and performance specifications of the textile materials having electromagnetic shielding properties are presented in Table 1.

Table 1. Performance specifications of electromagnetic shielding textiles in general and professional use [7]

\begin{tabular}{cccc} 
Grade & $\begin{array}{c}\text { Percentage of } \\
\text { Electromagnetic } \\
\text { Shielding (ES) }\end{array}$ & $\begin{array}{c}\text { Shielding } \\
\text { Effectiveness } \\
\text { (SE) in General } \\
\text { Use }\end{array}$ & $\begin{array}{c}\text { Shielding } \\
\text { Effectiveness } \\
\text { (SE) in Professional } \\
\text { Use }\end{array}$ \\
\hline 5 Excellent & $\mathrm{SE}>99.9 \%$ & $\mathrm{SE}>30 \mathrm{~dB}$ & $\mathrm{SE}>60 \mathrm{~dB}$ \\
4 Very Good & $99.9 \% \geq \mathrm{SE}>99 \%$ & $30 \mathrm{~dB} \geq \mathrm{SE}>20 \mathrm{~dB}$ & $60 \mathrm{~dB} \geq \mathrm{SE}>50 \mathrm{~dB}$ \\
3 Good & $99 \% \geq \mathrm{SE}>90 \%$ & $20 \mathrm{~dB} \geq \mathrm{SE}>10 \mathrm{~dB}$ & $50 \mathrm{~dB} \geq \mathrm{SE}>40 \mathrm{~dB}$ \\
2 Moderate & $90 \% \geq \mathrm{SE}>80 \%$ & $10 \mathrm{~dB} \geq \mathrm{SE}>7 \mathrm{~dB}$ & $40 \mathrm{~dB} \geq \mathrm{SE}>30 \mathrm{~dB}$ \\
1 Fair & $80 \% \geq \mathrm{SE}>70 \%$ & $7 \mathrm{~dB} \geq \mathrm{SE}>5 \mathrm{~dB}$ & $30 \mathrm{~dB} \geq \mathrm{SE}>20 \mathrm{~dB}$ \\
\hline
\end{tabular}

\footnotetext{
*: Corresponding author
}

E-mail: acyilmaz@cu.edu.tr 
Metals are stated as the most effective electromagnetic shielding materials; however, they are expensive and heavy. Furthermore, thermal expansion, oxidation and corrosion are remarkable problems during usage [8]. Polymer composites, on the contrary, are more attractive than metal coated and plated materials for variety of applications (defense, electrical and electronic etc.) due to their low weight, low cost, ease of processing and shaping, and corrosion resistance. In the last few years, conductive nanofiller/polymer composites have been widely explored due to their exceptional multifunctional properties (mechanical, electrical, thermal etc.) compared to the conventional conductive polymer composites (CPCs) which includes conductive fillers such as carbon fibers (CF), carbon black (CB), metal and ceramics. These composites have been generally prepared using high aspect ratio 1-D conductive nanofillers that include carbon nanotubes (CNTs), vapour grown carbon nanofibers (VGCNFs) and metal nanowires (MNWs) [9-11]. VGCNF increases the thermal stability of many polymers due to the high thermal stability of the nanofiber and restriction of polymer chain movement imposed by the nanofibers. High thermal conductivity and high aspect ratio of VGCNF give thermally conductive polymer composites at lower filler loading compared to conventional carbon fillers [12]. Polymers filled with conventional fillers have very limited applications in the EMI shielding market because of having less shielding capabilities.

The higher aspect ratio leads to better mechanical and shielding properties. Low electrical percolation threshold concentration can be obtained with the high aspect ratio of conductive nanofillers such as carbon based nanofibers. The high conductivity along with the high aspect ratio ensures that these nanofibers incorporated composites may have an adequate level of shielding at relatively low filler loading compared to the composites including nanoparticles or nano clays [12]. In addition, the fiber content of a composite structure has an evident influence on the composite failure strain and strength. In general, as the fiber content 
increases within the matrix, tensile strength also increases [13-20]. Failure mechanism researches [15,21-23] revealed that failure of the structure under tensile stress begins with the ruptures at the fiber tips due to stress concentration and propagation of these cracks along the fiber-matrix interface. As a result, it can easily be inferred that fiber concentration and naturally number of fiber tips are of great influence on determining the strength of the structure [24].

(a)

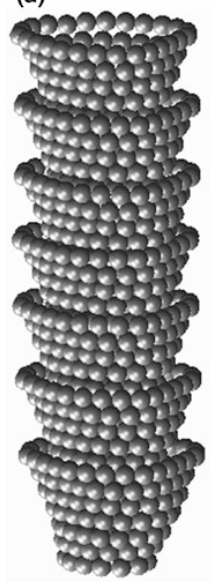

(b)

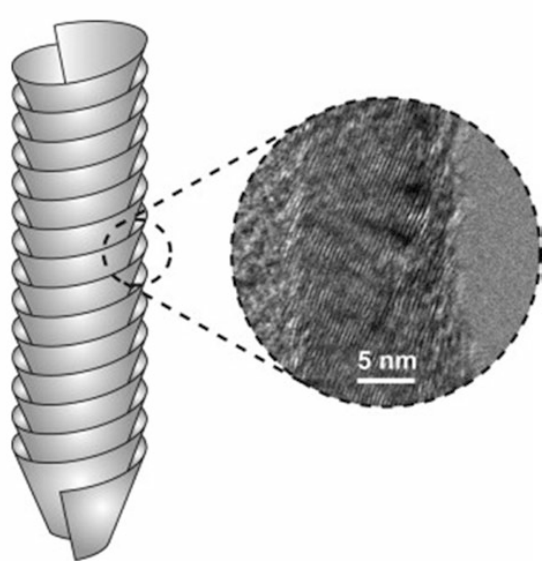

Figure 1. Schematic stacked-cup carbon nanofiber structure with a TEM image showing [54].

In this present work, VGCNFs were used as conductive and reinforcing nanofillers, and Polyvinylidene fluoride (PVDF) was utilized as polymer $\mathrm{r}$ matrix to prepare thermoplastic composites. Although, VGCNFs were launched earlier than CNTs to the research field, much less research was carried out for VGCNFs due to smaller diameter, lower density and better mechanical properties of CNFs. It is described that VGCNFs are hollow core nanofibers composed of a single graphite layer or double graphite layers that are stacked parallel or at a certain angle from the fiber axis [24,25]. The stacked layers are nested with each other and have different formations including bamboo-like, parallel and cup-stacked [26-28]. Since VGCNFs have much lower price compared to CNFs, and especially cup-stacked form 
contains more reactive carbon edges that can interact with the matrix better, they could be a potential alternative for manufacturing single filled, bi-filled and multi-filled synergistic reinforced composite structures for shielding purposes. The aim of this study is to prepare shielding nanocomposite structures, consist of various amounts of VGCNFs and PVDF, by compression molding, and characterize the mechanical properties as well as EMSE performance of these samples.

\section{Experimental Work}

\section{Materials}

The carbon nanofiller used in this study is graphitized VGCNF (PR-25-XT-LHT, Sigma Aldrich). PVDF was provided by Solvay. The properties of the CNFs and PVDFs are given in Table 2.

Table 2. The properties of VGCNFs and PVDF

\begin{tabular}{|ll|ll|}
\hline \multicolumn{2}{|c|}{ VGCNFs } & \multicolumn{2}{c|}{ PVDF } \\
\hline Type of the VGCNFs & $\begin{array}{l}\text { Graphitized, platelets } \\
\text { (conical) }\end{array}$ & Type of the PVDF & Solef ${ }^{\circledR} 1000$ series \\
Purity of CNFs & $>98 \%$ carbon basis & Volume Resistivity & $>10^{14} \mathrm{ohm} . \mathrm{cm}$ \\
D (diameter) & $100 \mathrm{~nm}$ & Density & $1.78 \mathrm{~g} / \mathrm{cm}^{3}$ \\
L (Long) & $20-200$ micron & Melting Point & $160-172{ }^{\circ} \mathrm{C}$ \\
Average pore volume & $0.12 \mathrm{~cm}^{3} / \mathrm{g}$ & Melt Flow Index (MFI) @ & 8 (g/10min) \\
& & $230^{\circ} \mathrm{C} / 2.16 \mathrm{~kg}$ & \\
Molecular Weight & $12.01 \mathrm{~g} / \mathrm{mol}$ & & \\
Density & $1.9 \mathrm{~g} / \mathrm{cm}^{3}$ & & \\
\hline
\end{tabular}

\section{Preparation of Nanocomposite Structures}

The VGCNFs/PVDF nanocomposites were prepared by melt compounding in twinscrew laboratory type compounder machine. The machine has six heating chambers in the extruder and an automatic feeding system. The working conditions of melt compounder are given in Table 3. At the end of the compounder extruder, the polymer strand was cooled in cold water bath and cut in pellets. Prior to compounding, the PVDF pellets and VGCNF 
powder were placed in a vacuum oven at $80{ }^{\circ} \mathrm{C}$ and $130{ }^{\circ} \mathrm{C}$, respectively for about 16 hours. 1 wt.\%, 3 wt.\%, 5 wt.\% and 8 wt.\% of VGCNFs were blended with PVDF and compounded together. The total amount of the masterbatches (VGCNFs/PVDF) was around 600 g. Finally, these pellets were dried in an oven for 12 hours at $80^{\circ} \mathrm{C}$.

The carbon nanofiber (VGCNF) and reinforced nanocomposites were weighed to find out the amount of carbon nanofiber used within the construction. And so, for nanocomposite structures, carbon nanofiber volume fraction was calculated according to standard by using (2) [51]:

$V_{f}=\frac{\rho_{m} \cdot w_{f}}{\left(\rho_{m} \cdot w_{f}+\rho_{f} \cdot w_{m}\right)}$

where $V_{f}$ volume fraction of fibers, $W_{f}$ weight of fibers, $W_{m}$ weight of matrix, $\rho_{f}$ density of fibers, $\rho_{m}$ density of matrix.

Table 3. Working conditions of melt compounder

\begin{tabular}{lc}
\hline Extruder Room Temperatures & $\begin{array}{c}{ }^{\circ} \mathrm{C} ; 205^{\circ} \mathrm{C} ; 210^{\circ} \mathrm{C} ; 209{ }^{\circ} \mathrm{C} ; \\
20{ }^{\circ} \mathrm{C} ; 210{ }^{\circ} \mathrm{C}\end{array}$ \\
Feeder Speed (\%) & 10 \\
Torque (\%) & 35 \\
Motor Rotation Speed (RPM) & 350 \\
Delivery Pressure (Bar) & 14 \\
\hline
\end{tabular}

The VGCNF/PVDF nanocomposite plates $(10 \times 10 \mathrm{~cm})$ were constructed by compression molding using Hursan compression molder (Hursan, Turkey). The compression molding conditions were as follows: temperature $195{ }^{\circ} \mathrm{C}$, holding time 5 min and pressure 15 MPa. The properties of nanocomposites are given in Table 4.

Table 4. Properties of nanocomposite structures

*: Corresponding author

E-mail: acyilmaz@cu.edu.tr 


\begin{tabular}{cccccc}
\hline Sample Code & $\begin{array}{c}\text { Thickness } \\
(\mathbf{m m})\end{array}$ & $\begin{array}{c}\text { Aerial } \\
\text { Weight } \\
\left(\mathbf{g} / \mathbf{m}^{2}\right)\end{array}$ & $\begin{array}{c}\text { VGCNF } \\
\text { content } \\
\text { (wt.\%) }\end{array}$ & $\begin{array}{c}\text { PVDF } \\
\text { content } \\
\text { (wt.\%) }\end{array}$ & $\begin{array}{c}\text { Fiber } \\
\text { Volume } \\
\text { Fraction }\end{array}$ \\
\hline PVDF & 1.97 & 3346.91 & 0 & 100 & ---- \\
CNF/PVDF & 2.14 & 3651.31 & 1 & 99 & 0.009 \\
CNF/PVDF & 2.13 & 3683.88 & 3 & 97 & 0.028 \\
CNF/PVDF & 2.14 & 3678.86 & 5 & 95 & 0.046 \\
CNF/PVDF & 2.13 & 3663.18 & 8 & 92 & 0.075 \\
\hline
\end{tabular}

\section{SEM Analyses of the Structures}

The VGCNF/PVDF nanocomposites were characterized by Scanning Electron Microscopy (SEM, JSM-5910 LV from JEOL). First of all, samples were coated with a thin gold palladium (20/80\%) layer using a sputter coater from Polaron (SC7620) and the morphology of the structures were observed by SEM analysis at an accelerating voltage of 20 $\mathrm{kV}$.

\section{Measurement of Mechanical Properties}

The specimens were tested using Devotrans Universal test machine at a crosshead speed of $2 \mathrm{~mm} / \mathrm{min}$. Impact strength was checked by means of CHEAST charpy impact resistance. Charpy impact tests were performed to study the energy absorption of the nanocomposites. For each sample, five specimens were tested at room temperature and the average of the five samples was taken as the final result $[29,30]$.

\section{Electromagnetic Shielding Effectiveness Measurements (EMSE)}

\footnotetext{
*: Corresponding author

E-mail: acyilmaz@cu.edu.tr
} 
A coaxial transmission line method was used to test the EMSE of VGCNFs/PVDF nanocomposites. The specimens were prepared with a standard test size of various thicknesses. The outer ring of the specimen was $133 \mathrm{~mm}$ in diameter. Two specimens were required to be produced for the test, one for reference and another for load testing. Various researchers have described the detailed set-up and testing procedure using a plane-wave electromagnetic field in the frequency range of 15-3000 MHz. A network analyzer (Rohde Schwarz, ZVL) to generate and receive the EM signals and a shielding effectiveness test fixture (Electro-Metrics, Inc., EM-2107A) in Figure 2(a) were used to measure the EMSE, in $\mathrm{dB}$, in this investigation. The shielding effectiveness was determined from (1), which is the ratio of the incident field to that which passes through the material where $\mathrm{P}_{1}$ (Watts) is received power with the nanocomposite presence and $\mathrm{P}_{2}$ (Watts) is received power without the nanocomposite presence. The input power used was $0 \mathrm{~dB}$, corresponding to $1 \mathrm{~mW}[4,31]$.

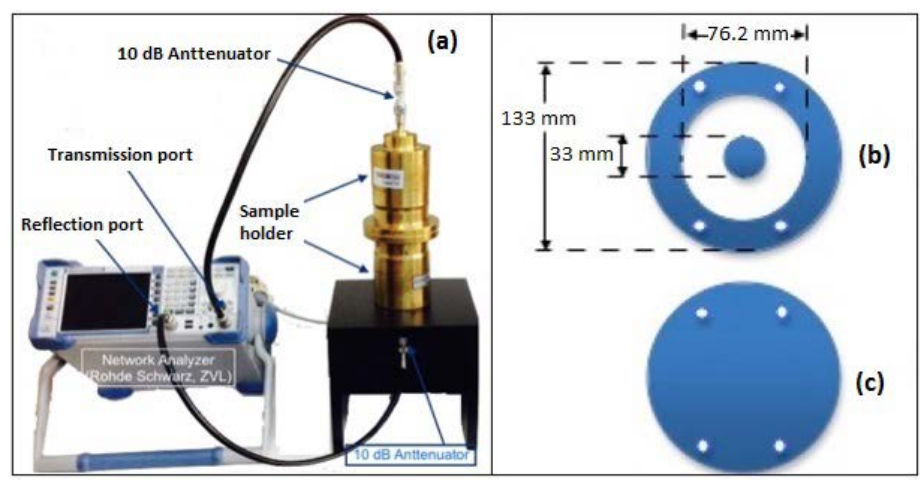

Figure 2. (a) Set up of the electromagnetic shielding effectiveness testing apparatus; (b) and (c) specimens for reference and load, respectively.

This standard determined the shielding effectiveness of the nanocomposite using the insertion-loss method. The technique involved irradiating a flat, thin sample of the base material with an EM wave over the frequency range of interest, utilizing a coaxial transmission line with an interrupted inner conductor and a flanged outer conductor. A reference measurement for the empty cell was required for the shielding effectiveness *: Corresponding author E-mail: acyilmaz@cu.edu.tr 
assessment (Figure 2(b)). The reference sample was placed between the flanges in the middle of the cell, covering only the flanges and the inner conductors. A load measurement was performed on a solid disk shape, which had a diameter the same as that of the flange (Figure 2(c)). The reference and the load measurement were performed on the same material. The shielding effectiveness was determined from (3), which is the ratio of the incident field to that which passes through the material [31].

$$
\begin{aligned}
& \mathrm{EMSE}=10 \log \left(\frac{\mathrm{P}_{1}}{\mathrm{P}_{2}}\right) \\
& \mathrm{A}_{\mathrm{b}}=1-T_{\mathrm{r}}-R_{\mathrm{e}} \\
& R_{\mathrm{e}}=\left|\frac{E_{r}}{E_{i}}\right|^{2}=\mid\left. S_{11}\left(\text { or } S_{22}\right)\right|^{2} \\
& T_{\mathrm{r}}=\left|\frac{E_{t}}{E_{i}}\right|^{2}=\mid\left. S_{21}\left(\text { or } S_{12}\right)\right|^{2}
\end{aligned}
$$

The reflectance $\left(R_{\mathrm{e}}\right)$ and the transmittance $\left(T_{\mathrm{r}}\right)$ of the nanocomposites were also measured and the absorbance $\left(A_{b}\right)$ was calculated using the equation (4) where, $R_{e}$ and $T_{r}$ are the square of the ratio of reflected $\left(E_{r}\right)$ and transmitted $\left(E_{t}\right)$ electric fields to the incident electric field ( $\left.\mathrm{E}_{i}\right)$, respectively, as shown in equations (5) and (6). $R_{\mathrm{e}}$ and $T_{\mathrm{r}}$ were obtained by the measurement of S-parameters, $S_{11}$ (or $S_{22}$ ) and $S_{12}$ (or $S_{21}$ ) for the reflection and the transmission, respectively [32,33]. For each of the samples, five measurements for EMSE tests were carried out. The shielding effectiveness measurements were conducted between the frequency ranges of 15-3000 MHz.

\section{Results and Discussion}

\section{Structural Analysis of the VGCNFs/PVDF Nanocomposites}

\footnotetext{
*: Corresponding author

E-mail: acyilmaz@cu.edu.tr
} 
SEM images of PVDF with various CNF concentrations are depicted in Figure 3. Increased bulk density of the structure was clearly observed from the SEM analysis. Also, good level of VGCNFs dispersion occurred for all concentrations. The satisfactory dispersion of nanofibers within the matrix may be associated with the selection of proper process parameters and the compatibility between nanofillers and PVDF polymer matrix. It was also observed that while the fiber content increased in the matrix, fiber quantity per volume is also expected to increase which leads to higher the amount of the interconnected network among the fibers.

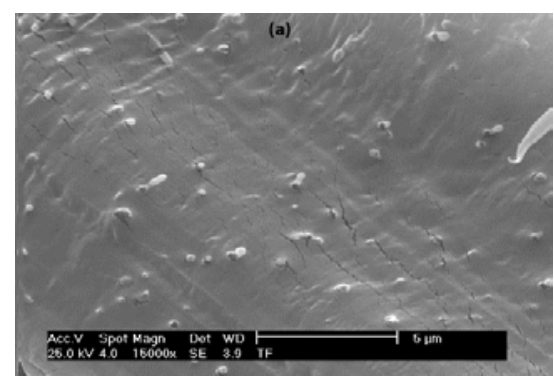

(a)

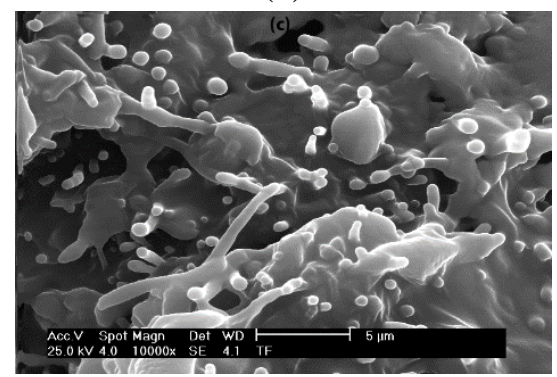

(c)

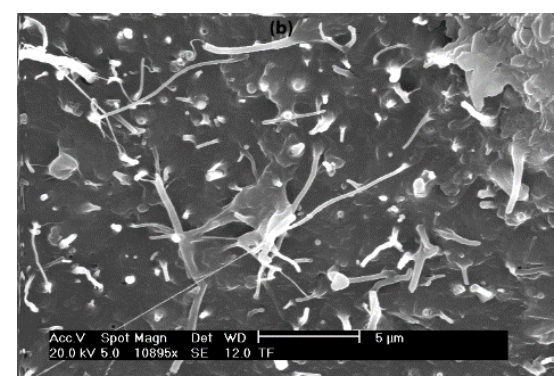

(b)

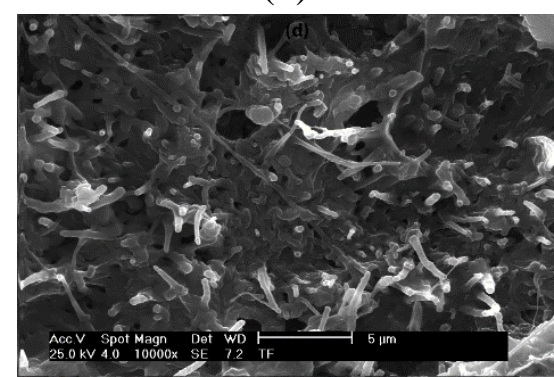

(d)

Figure 3. SEM images of PVDF matrix with various CNF concentrations (a) $1 w t \%$ CNF, (b) $3 w t \%$ CNF, (c) $5 w t \%$ CNF, (d) $8 w t \%$ CNF 


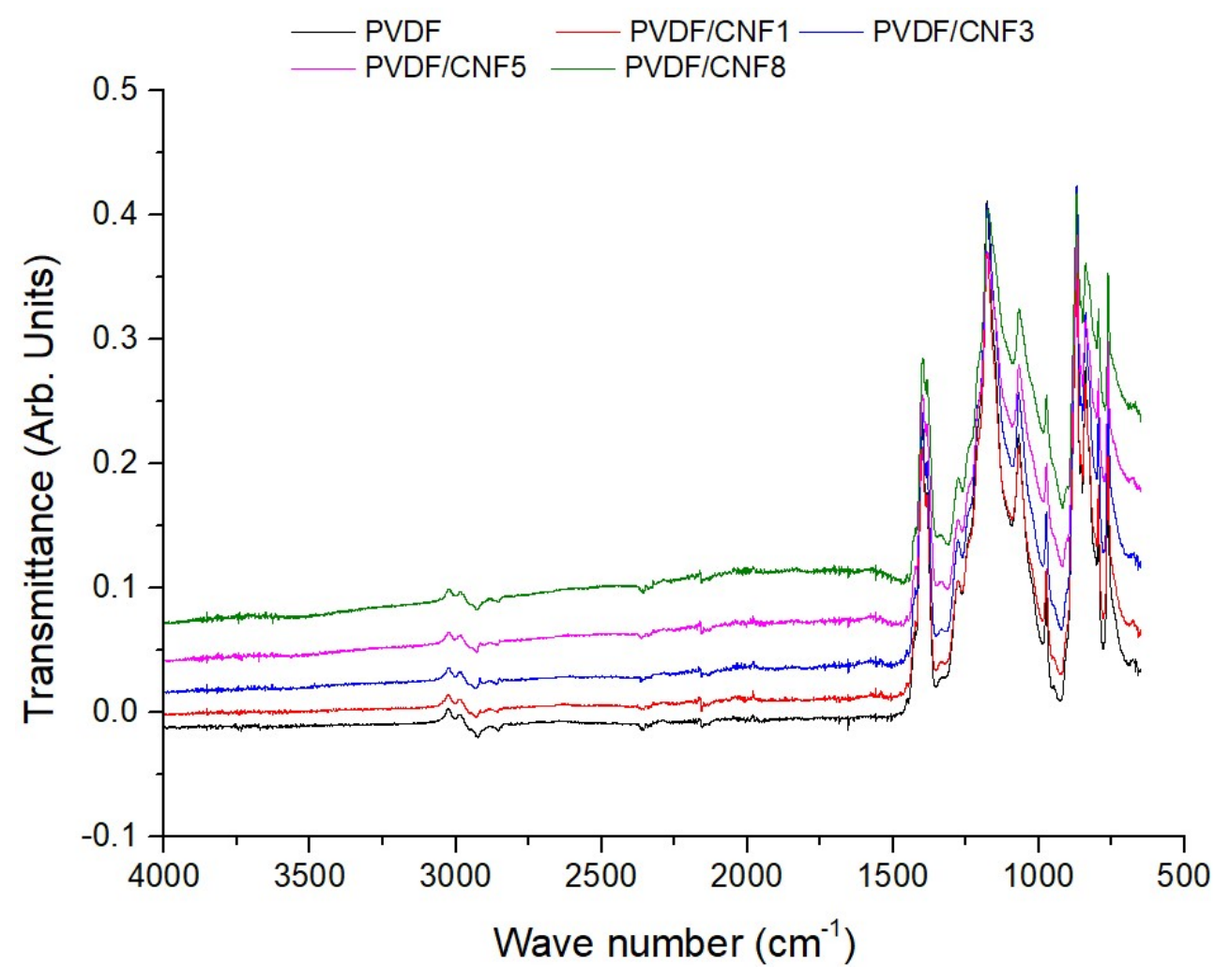

Figure 4. FTIR spectra of PVDF matrix with various CNF concentrations 1,3,5 and 8 wt\%.

\section{Mechanical Characteristics of the VGCNFs/PVDF Nanocomposites}

As the weight ratio of VGCNFs increases in the matrix, tensile strength also increases where elongation is inversely proportional to VGCNFs wt\%. The maximum tensile strength ( $\sim 50 \mathrm{MPa}$ ) and minimum elongation ( 7\%) were obtained for 8 wt\% of VGCNFs in the matrix when compared to sole PVDF with $44 \mathrm{MPa}$ tensile strength. The mechanical properties of carbon nanofibers reinforced polymers depend on volume fraction of the fibers in the matrix [34]. At high VGCNFs compositions, when load is applied to the composite structure, VGCNFs separate from the matrix and strain energy is dissipated which entails impediment of failure of the matrix, finally increased tensile strength (Table 5). 
Charpy test is a renowned method for evaluating impact toughnesses of structures. Nevertheless, it is a way of analyzing absorbed energy which encompasses sample width (W), length (L) and thickness (h). In this study, square shaped samples with 10x10 cm (LxW) and $\mathrm{h}$ of $2.5 \mathrm{~mm}$ were used. Considering impact energy to be totally absorbed by span size defined specimen volume, the impact energy per unit volume (e) may be found by [50] where $U$ is the measured impact energy:

$$
e=\frac{U}{W L h}
$$

In Charpy impact tests, the load was applied normal to the laminates. The test bench consists of anvils where the sample is freely supported, a pendulum attached to a rotating arm. The pendulum with a defined mass is released from a defined height and hits the sample in the middle, drawing a circular trajectory; transfers kinetic energy and rises to a height. Difference between heights is directly proportional to the energy absorbed by the sample. When a composite structure is exposed to impact, elastic deformation is formed by a part of the energy. The rest of the energy is dissipated through the material and induces plastic deformation, such as fiber breakage, delamination, fiber-matrix debonding and matrix cracking. The energy absorbed by the specimens is an indication of the magnitude of damage. Five specimens were tested under constant load and pendulum height and averages of the 5 values were taken into account for each test. As the CNF concentration in PVDF matrix was increased, absorbed energy also increased in general. This can be attributed to the increment of bulk density with the increase in CNF amount. More fibers in the matrix means more energy dissipation through the structure and eventually increased energy absorption capacity (Table 5). Nevertheless, to an extent, as the VGCNFs ratio is augmented in the matrix, bulk 
density also increases due to higher density of VGCNFs than that of sole PVDF in which load transfer from the resin epoxy to the fibers is formed. In this context, increased bulk density can reduce number of flaws in the structure and stress concentration possibility as well. Voids may be formed by the VGCNFs in the matrix which induce high surface area and much more absorbed fracture energy across the matrix [35]. As to enhanced fracture behavior, modulus of the structure also increases with the increment in VGCNFs ratio. With 8 wt\% of VGCNFs, the modulus is $>70 \mathrm{MPa}$, which is the maximum among all the cases (Table 5).

Table 5. Tensile strength, Elongation, Charpy's impact fracture energy and E-modulus of

CNF/PVDF nanocomposites

\begin{tabular}{ccccc}
\hline $\begin{array}{c}\text { CNF content } \\
(\boldsymbol{w t} \%)\end{array}$ & $\begin{array}{c}\text { Tensile Strength } \\
\mathbf{( M P a )}\end{array}$ & $\begin{array}{c}\text { Elongation } \\
\mathbf{( \% )}\end{array}$ & $\begin{array}{c}\text { E-Modulus } \\
\mathbf{( M P a )}\end{array}$ & $\begin{array}{c}\text { Charpy Impact } \\
\mathbf{( k J / m 2 )}\end{array}$ \\
\hline $\mathbf{0}$ & 44.39 & 13.45 & 1211 & 37.77 \\
$\mathbf{1}$ & 47.13 & 12.02 & 1284 & 50.80 \\
$\mathbf{3}$ & 48.12 & 9.80 & 1366 & 52.02 \\
$\mathbf{5}$ & 49.21 & 9.36 & 1420 & 57.27 \\
$\mathbf{8}$ & 51.45 & 7.42 & 1666 & 59.17 \\
\hline
\end{tabular}

\section{EMSE Performances of the VGCNFs/PVDF Nanocomposites}

Figure 6 shows EMSE values of VGCNFs/PVDF nanocomposites, consisting of different wt. \% of carbon nanofibers, in the 15-3000 MHz frequency ranges. As the frequency increases, EMSE values of all VGCNFs/PVDF nanocomposites increase as well. There is an inverse relationship between wavelength and frequency. In this context, the frequency increases with decreasing of the wavelength [7, 36-39]. It is clearly seen that, as the amount of VGCNFs used in nanocomposites increases, EMSE values also increase in the 15-3000 MHz frequency ranges as a result of the decrease in electrical resistivity of the structures increase. Conductivity is an effective parameter on the electromagnetic shielding effectiveness [32, 4043]. Electrical resistivity measurements were conducted via 4 point-probe system [52] as seen

*: Corresponding author

E-mail: acyilmaz@cu.edu.tr 
in Figure 5 and the outcomes of electrical resistance and resistivity measurements are depicted in Table 7.

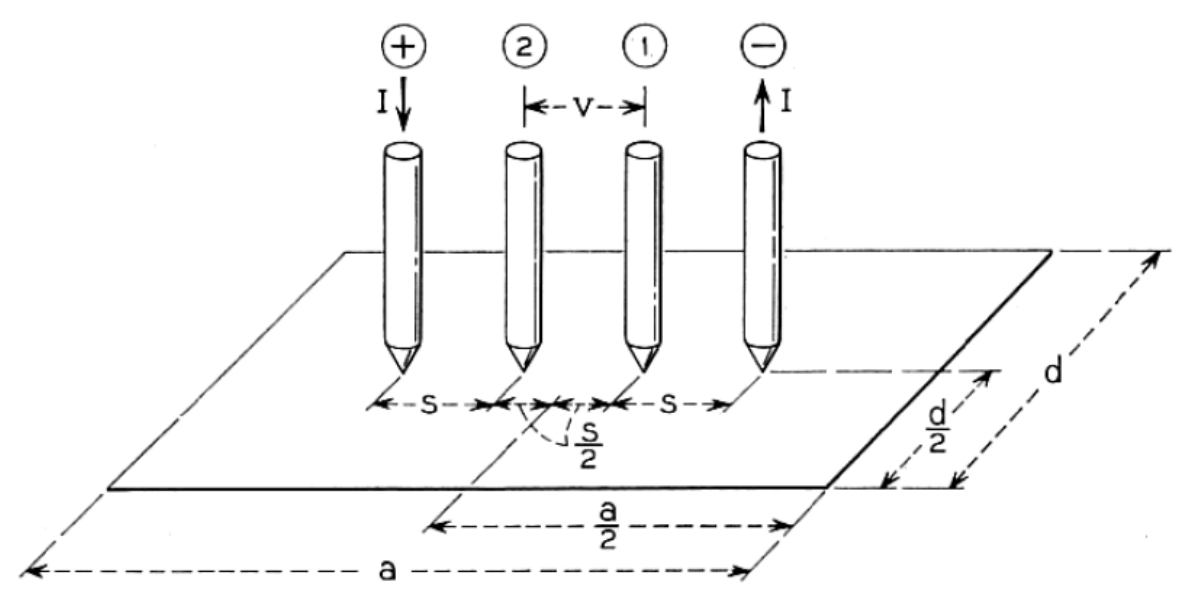

Figure 5. Four point probe schematics

Here;

$\mathrm{d}$ is used for $\frac{d_{d i m}}{s}$

a is used for $\frac{a_{d i m}}{s}$

$V=\operatorname{I} p_{s} \frac{1}{\pi}\left[\frac{\pi}{d}+\ln \left(1-e^{-\frac{4 \pi}{d}}\right)-\ln \left(1-e^{-2 \pi / d}\right)+\sum_{m=1}^{\infty} \alpha m\right]$

$R_{S}=R_{\text {avg }} \cdot C$

$p_{s}=R_{s} \cdot t$

$V=I \cdot p_{s} \cdot \frac{1}{c}$

$\alpha_{m}=\frac{1}{m} e^{-2 \pi(\alpha-2) m / d} \frac{\left(1-e^{-6 \pi m / d}\right)\left(1-e^{-2 \pi m / d}\right)}{\left(1+e^{-2 \pi a m / d}\right)}$

where; $d_{d i m}$ is the sample width (mm), $a_{\text {dim }}$ is the sample length (mm), $p_{s}$ is the sheet resistivity $(\Omega \mathrm{cm}), C$ is the correction factor, $a_{m}$ is the summation term, $V$ is the voltage measured, $I$ is the magnitude of source current (amps), $R_{s}$ is the sheet resistance ( $\Omega$ /square), $t$ is the thickness (cm). 
The sheet resistance $(\Omega / \mathrm{sq})$ is calculated by multiplying the average resistance with the correction factor C:

$R_{s}=R_{a v g} \cdot C$

Then the resistivity $(\Omega . \mathrm{cm})$ is calculated by [53]:

$\rho=R_{s} \cdot t$

Table 6. Electrical resistance and resistivity values

\begin{tabular}{cccc}
\hline & Resistance $(\boldsymbol{\Omega})$ & Sheet Resistance $\mathbf{( \Omega / s q})$ & Resistivity $(\mathbf{\Omega} . \mathbf{c m})$ \\
\hline PVDF & $4,53 \mathrm{E}+08$ & $1,99 \mathrm{E}+09$ & $3,92 \mathrm{E}+08$ \\
1-PVDF & $4,05 \mathrm{E}+08$ & $1,78 \mathrm{E}+09$ & $3,80 \mathrm{E}+08$ \\
3-PVDF & $3,69 \mathrm{E}+08$ & $1,62 \mathrm{E}+09$ & $3,44 \mathrm{E}+08$ \\
5-PVDF & $3,45 \mathrm{E}+02$ & $1,51 \mathrm{E}+03$ & $3,24 \mathrm{E}+02$ \\
8-PVDF & $1,25 \mathrm{E}+02$ & $5,49 \mathrm{E}+02$ & $1,17 \mathrm{E}+02$ \\
\hline
\end{tabular}

The nanocomposites with 8 wt.\% of VGCNFs obtained the highest EMSE value (17.3 $\mathrm{dB}$ ) in the $2100 \mathrm{MHz}$ frequency. Findings revealed that the amount and the dispersion of VGCNFs had considerable impact on the electromagnetic shielding effectiveness results due to the increment in the numbers of conductive fiber network in the composites. Moreover, it was noticed that the EMSE performance of each composite increased almost cumulatively while the content of VGCNFs increased in the structures due to the high aspect ratio triggered the conductive network formation at even very low nanofiller loading [12].

Figure 7 and 8 illustrate absorbance and reflectance values of VGCNFs/PVDF nanocomposites produced with carbon nanofibers at different weight ratios (1 wt. \%, 3 wt. \%, 5 wt. \%, 8 wt. \%) in the 15-3000 MHz frequency ranges. The reflection and absorption of electromagnetic waves are related with the properties of conductive fillers. For instance, carbon fibers are defined as more absorbent materials rather than being reflective in terms of the attenuation of electromagnetic waves in especially increasing frequencies [44-47]. 
Therefore, it was seen that absorbance values of the VGCNFs/PVDF nanocomposites were higher than reflectance values at between $15-3000 \mathrm{MHz}$ frequency range. Similar results were obtained by many researchers for different kinds of conductive nano filler materials [49]. Another reason for this result could be explained by the decrease in gaps between the fibers with increasing nanofiller loading, consequently enhancing the absorption loss [48].

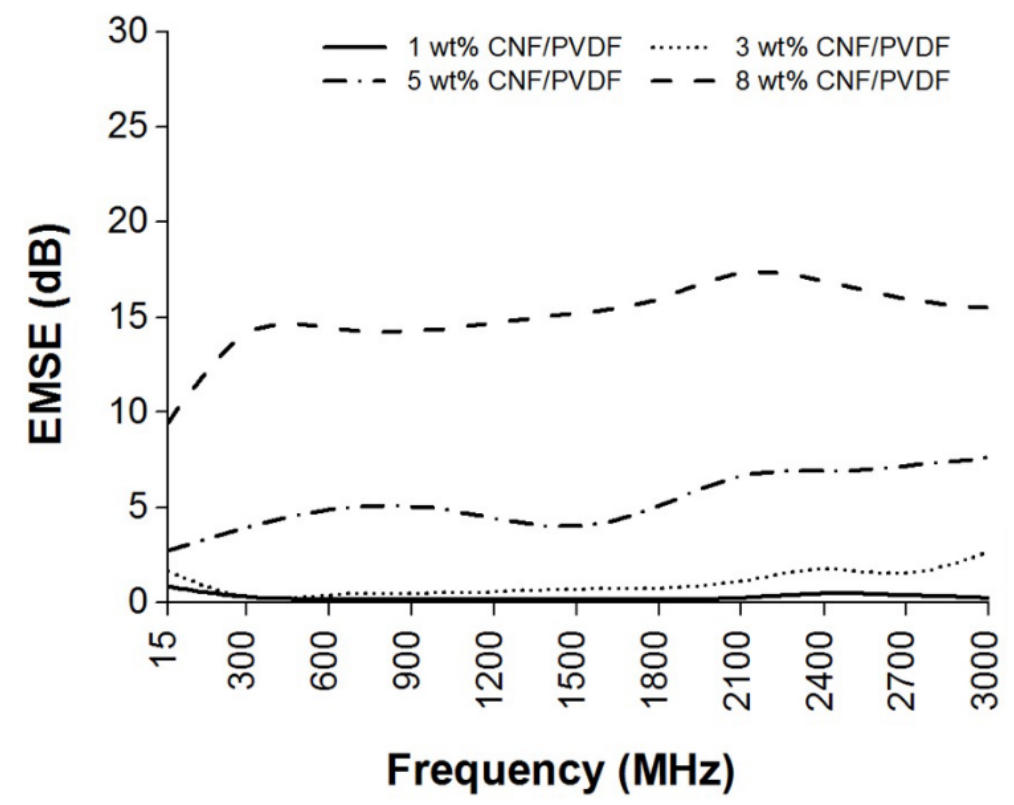

Figure 6. Electromagnetic shielding effectiveness (EMSE) of CNF/PVDF nanocomposites.

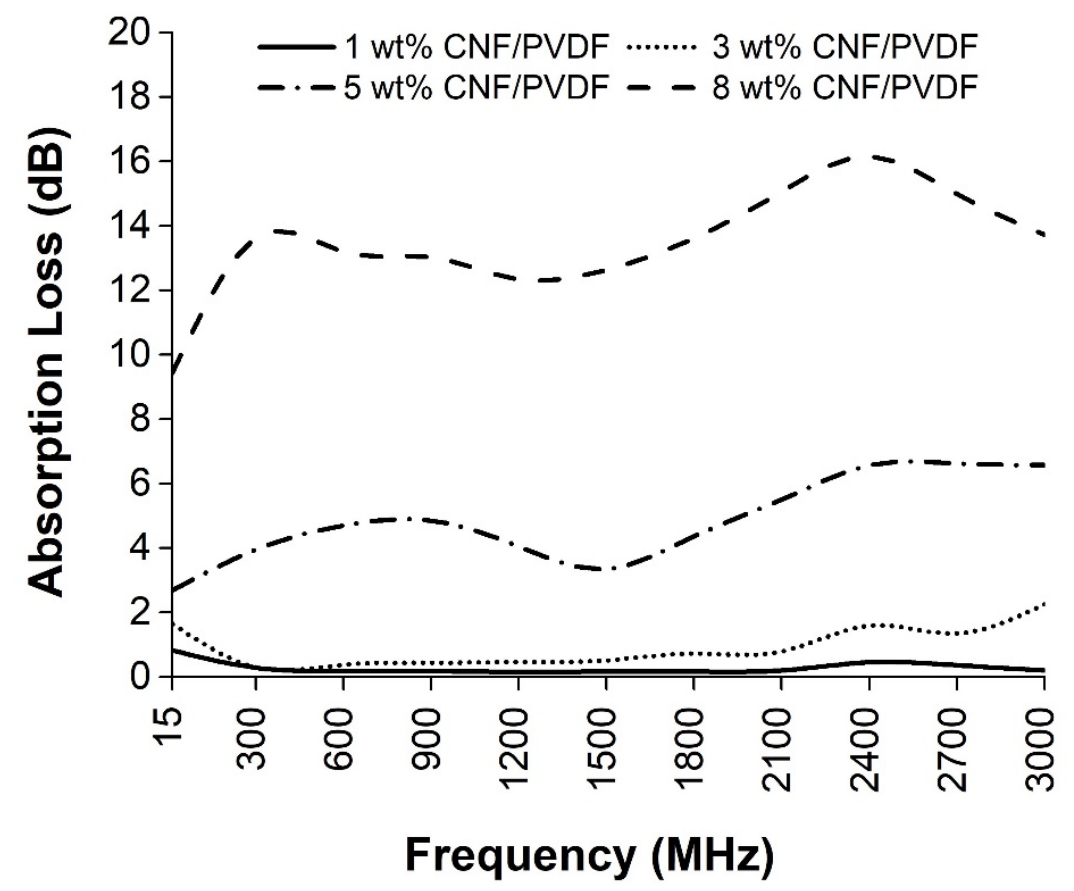

\footnotetext{
*: Corresponding author
}

E-mail: acyilmaz@cu.edu.tr 
Figure 7. Absorbance behaviour of CNF/PVDF nanocomposites between $15-3000 \mathrm{MHz}$ frequency range

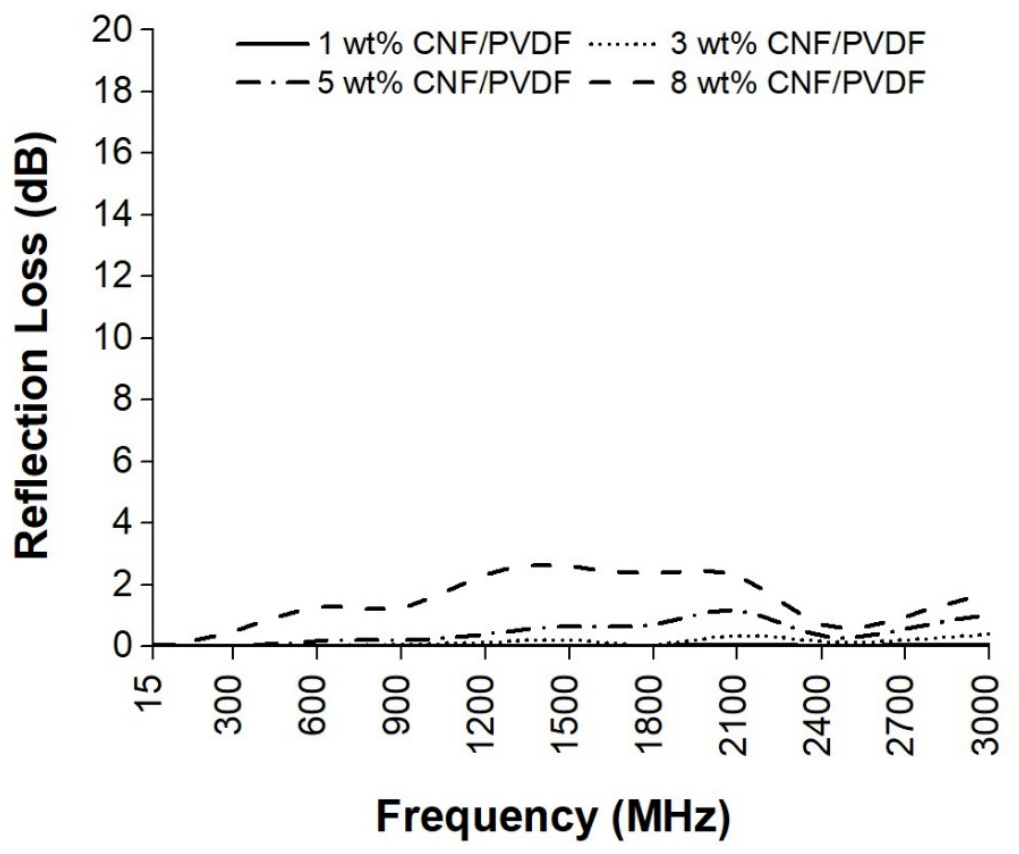

Figure 8. Reflectance behaviour of CNF/PVDF nanocomposites between 15-3000 MHz frequency range

\section{Conclusions}

In this research, it was observed that CNF ratio increment in nanocomposites yields a significant increase in electromagnetic shielding effectiveness and mechanical properties. Nanocomposites loaded with CNF above $5 \mathrm{wt} \%$ are suitable for electromagnetic shielding applications. The highest electromagnetic shielding found in this work was $17.3 \mathrm{~dB}$ for $8 \mathrm{wt}$. \% VGCNFs/PVDF nanocomposite. It was found that the electromagnetic waves shielded by VGCNFs/PVDF nanocomposites with 8 wt. \% VGCNFs were about $90 \%$ between 15-3000 $\mathrm{MHz}$ frequency range which is proper for general use. Nonetheless, due to higher density of 
CNFs than that of sole PVDF, matrix with nano fibers showed higher bulk density which yielded load transfer from the resin epoxy to the fibers and finally enhanced energy absorption capacity. On the other hand, as the weight ratio of CNF increases in the matrix, tensile strength also increases where elongation is inversely proportional to CNF wt\%. At high CNF compositions, when load is applied to the composite structure, CNFs separate from the matrix and strain energy is dissipated which entails impediment of failure of the matrix, finally increased tensile strength. In the context of Young modulus, $8 \mathrm{wt} \%$ intermingled CNF in PVDF matrix had approximately 1.2 times of sole PVDF. In other words, the mechanical properties of carbon nanofibers reinforced polymers strongly depend on volume fraction of fibers in the matrix. The low price of VGCNFs compared to competitive fillers such as CNTs will be one of the major determinants of their widespread commercial use in the polymer industry. VGCNF/PVDF composites have potential applications in many fields including: Electromagnetic wave shielding applications, ESD protection, batteries, sensors and automotive industry.

\section{Acknowledgement}

Authors would like to thank Marmara University, Faculty of Technology, Dept. of Textile Engineering Research Laboratory staff and Cukurova University Scientific Research Projects (project no: 6188) for their financial support.

\section{References}

[1] D.R. Paul, L.M. Robeson, Polymer nanotechnology: nanocomposites, Polymer 49 (2008) 3187-3204. 
[2] M.H. Al-Saleh, S. Uttandaraman, Review of the mechanical properties of carbon nanofiber/polymer composites, Composites: Part A 42 (2011) 2126-2142.

[3] R. Erdem, Evaluation of electromagnetic shielding effectiveness of multi-axial fabrics and their reinforced PES composites, Bulletin of Materials Science 39 (2016), 963-970.

[4] M.S. Ozen, E. Sancak, A. Beyit, I. Usta, M. Akalın, Investigation of electromagnetic shielding properties of needle-punched nonwoven fabrics with stainless steel and polyester fiber, Text.Res. J. 83 (2013), 849.

[5] K.B. Cheng, S. Ramakrishna, K.C. Lee, Electromagnetic shielding effectiveness of copper/glass fiber knitted fabric reinforced polypropylene composites, Composites Part A: App. Sci. and Man. 31 (2000) 1039-1045.

[6] Y.Y. Wang, X.L. Jing, Intrinsically conducting polymers for electromagnetic interference shielding, Polym. Advan. Technol. 16 (2005), 344.

[7] FTTS-FA-003: “Test method of specified requirements of electromagnetic shielding textiles”, 2003, Committee for Conformity Assesment on Accreditation and Certification of Functional and Technical Textiles, Taiwan, (2003) 1-4.

[8] H.C. Chen, K.C. Lee, J.H. Lin, M. Koch, Fabrication of conductive woven fabric and analysis of electromagnetic shielding via measurement and empirical equation, J. Mater. Process. Technol. 184 (2007), 124-130.

[9] B. Maruyama, H. Alam, Carbon nanotubes and nanofibers in composite materials. SAMPE J. 38 (2002), 59-70.

[10] V.Z. Mordkovich, Carbon nanofibers: a new ultrahigh-strength material for chemical technology, Theor Found. Chem. Eng. 37 (2003), 429-438.

[11] G.G. Tibbetts, M.L. Lake, K.L. Strong, B.P. Rice, A review of the fabrication and properties of vapor-grown carbon nanofiber/polymer composites. Compos. Sci. Technol. (67) 2007, 1709-1718.

*: Corresponding author

E-mail: acyilmaz@cu.edu.tr 
[12] M.H. Al-Saleh, U. Sundararaj, A review of vapor grown carbon nanofiber/polymer conductive composites, Carbon, 47 (2009), 2-22.

[13] H. Bijsterbosc, R.J. Gaymans, Polyamide 6-long glass fiber injection moldings. Polym. Compos. 16 (1995), 363-369.

[14] L. Biolzi, L. Castellani, I. Pitacco, On the mechanical response of short fibre reinforced polymer composites, J. Mater. Sci. 29 (1994), 2507-2512.

[15] P.T. Curtis, M.G. Bader, J.E. Bailey, The stiffness and strength of a polyamide thermoplastic reinforced with glass and carbon fibres, J. Mater. Sci. 13 (1978), 377390.

[16] J. Denault, T. Vu-Khanh, B. Foster, Tensile properties of injection molded long fiber thermoplastic composites. Polym. Compos. 10 (1989), 313-321.

[17] K.C. Ho, J.R. Hwang, J.L. Doong, Tensile properties of short glass fibre reinforced polycarbonate, Polym. Compos. 4 (1996), 563-575.

[18] M. Joshi, S.N. Maiti, A. Misra, Influence of fiber length, fiber orientation, and interfacial adhesion on poly(butylene terephthalate)/polyethylene alloys reinforced with short glass fibers, Polym. Compos. 15 (1994), 349-358.

[19] J.R. Sarasua, P.M. Remiro, J. Pouyet, The mechanical behavior of PEEK short fibre composites, J. Mater. Sci. 30 (1995), 3501-3508.

[20] M.L. Shiao, S.V. Nair, P.D. Garrett, R.E. Pollard, Effect of glass-fibre reinforcement and annealing on microstructure and mechanical behavior of nylon 6,6. Part II. Mechanical behaviour, J. Mater. Sci. 29 (1994), 1739-1752.

[21] S.Y. Fu, T. Kurauchi, S. Sato, O. Kamigaito, Microfailure behaviour of randomly dispersed short fibre reinforced thermoplastic composites obtained by direct SEM observation, J. Mater. Sci. 26 (1991), 3891-3898. 
[22] K. Takahashi, N.S. Choi, Influence of fibre weight fraction on the failure mechanisms of poly(ethylene terephthalate) reinforced by short-glass fibres, J. Mater. Sci. 26 (1991), 4648-4656.

[23] N. Sato, T. Kurauchi, S. Sato, O. Kamigaito, Mechanism of fracture of short glass fibrereinforced polyamide thermoplastic, J. Mater. Sci. 19 (1984), 1145-1152.

[24] T. Uchida, D.P. Anderson, M.L. Minus, S. Kumar, Morphology and modulus of vapor grown carbon nano fibers, J. Mater. Sci. 41 (2006), 5851-5856.

[25] H. Miyagawa, M.J. Rich, L.T. Drzal, Thermo-physical properties of epoxy nanocomposites reinforced by carbon nanotubes and vapor grown carbon fibers, Thermochim. Acta, 442 (2006), 67-73.

[26] E.T. Thostenson, C.Y. Li, T.W. Chou, Nanocomposites in context. Compos. Sci. Technol. 65 (2005), 491-516.

[27] V.I. Merkulov, D.H. Lowndes, Y.Y. Wei, G. Eres, E. Voelkl, Patterned growth of individual and multiple vertically aligned carbon nanofibers, Appl. Phys. Lett. 76 (2000), 3555-3557.

[28] M. Endo, Y.A. Kim, M. Ezaka, K. Osada, T. Yanagisawa, T. Hayashi, et al. Selective and efficient impregnation of metal nanoparticles on cup-stacked-type carbon nanofibers, Nano. Lett. 3 (2003), 723-726.

[29] ISO 179-1: “Plastics: Determination of Charpy impact properties”, 2010.

[30] ASTM D 3039/D 3039M-07: “Standard test method for tensile properties of polymer matrix composite materials” (2010).

[31] ASTM D4935-10: “Standard test method for measuring the electromagnetic shielding effectiveness of planar materials" (2010). 
[32] M.S. Kim, H.K. Kim, S.W. Byun, S.H. Jeong, Y.K. Hong, J.S. Joo, K.T. Song, J.K. Kim, C.J. Lee, J.Y. Lee, PET fabric/Polypyrrole composite with high electrical conductivity for EMI shielding, Syn. Metals, 126 (2002), 233-239.

[33] M.K. Erdogan, M. Karakisla, M. Sacak, Preparation, characterization and electromagnetic shielding effectiveness of conductive polythiophene/poly(ethylene terephthalate) composite fibers, J. of Macro. Sci. Part A: Pure and Applied Chem. 49 (2012), 473-482.

[34] S.R. Dhakate, A. Chaudhary, A. Gupta, A.K. Pathak, B.P. Singh, K.M. Subhehar, T. Yokozeki, Excellent mechanical properties of carbon fiber semi-aligned electrospun carbon nanofiber hybrid polymer composites, Royal Soc. of Chem. 6 (2016), 3671536722.

[35] M.A. Caminero, G.P. Rodriguez, V. Munoz, Effect of stacking sequence on Charpy impact and flexural damage behavior of composite laminates, Comp. Struc. 136 (2015), 345-357.

[36] H.G. Ortlek, C. Gunesoglu, G. Okyay, Y. Turkoglu, Investigation of electromagnetic shielding and comfort properties of single jersey fabrics knitted from hybrid yarns containing metal wire, Tekstil ve Konfeksiyon 22 (2012), 90-101.

[37] R. Perumalraj, B.S. Dasaradan, R. Anbarasu, P. Arokiaraj, S.L. Harish, Electromagnetic shielding effectiveness of copper core-woven fabrics, J. of the Textile Ins. 100 (2009), $512-524$.

[38] K.B. Cheng, Electromagnetic shielding effectiveness of the twill copper woven fabrics, J. of Rein. Plastics and Compos. 25 (2006), 699-709.

[39] J.S. Roh, Y.S. Chi, T.J. Kang, S.W. Nam, Electromagnetic shielding effectiveness of multifunctional metal composite fabrics, Textile Research Journal, 78 (2008), 825-835. 
[40] T. Kim, D.D.L. Chung, Mats and fabrics for electromagnetic interference shielding, J. of Mat. Eng. and Perf. 15 (2006), 295-298.

[41] D.D.L. Chung, Electromagnetic interference shielding effectiveness of carbon materials, Carbon 39 (2001), 279-285.

[42] S. Palamutcu, A. Ozbek, C. Karpuz, N. Dag, Electrically conductive textile surfaces and their electromagnetic shielding efficiency measurement, Tekstil ve Konfeksiyon, 3 (2010), 199-207.

[43] K.B. Cheng, T.W. Cheng, K.C. Lee, T.H. Ueng, W.H. Hsing, Effects of yarn constitutions and fabric specifications on electrical properties of hybrid woven fabrics, Composites Part A: Applied Sci. and Manuf. 34 (2003), 971-978.

[44] G.H. Kang, S.H. Kim, Electromagnetic wave shielding effectiveness based on carbon microcoil-polyurethane composites, J. of Nanomat. 2014 (2014), 1-6.

[45] S. Rea, D. Linton, E. Orr, J. Connell, Electromagnetic shielding properties of carbon fibre composites in avionic systems, Microwave Review (2005), 29-32.

[46] Y. Wu, S. Zhous, Z. Xu, W. Yu, Effect of carbon fiber buckling waved arrangement on the absorption of electromagnetic wave, Asia Pacific Conf. on Env. Sci. and Tech. Adv. in Bio. Eng. (2012).

[47] K. Li, C. Wang, H. Li, G. Jiao, J. Wei, Study on the electromagnetic interference of CFRC composites by reflectivity, J. Mat. Sci. Tech. 24 (2008), 2265-2271.

[48] M. Arjmand, T. Apperley, M. Okoniewski, U. Sundararaj, Comparative study of electromagnetic interference shielding properties of injection molded versus compression molded multi-walled carbon nanotube/polystyrene composites, Carbon 50 (2012), 5126-5134. 
[49] M.H. Al-Saleh, W.H. Saadeh, U. Sundararaj, EMI shielding effectiveness of carbon based nanostructured polymeric materials: A comparative study, Carbon 60 (2013), $146-156$.

[50] A. Fazal, K.F. Fansey, Viscoelastically prestressed polymeric matrix composites, Effects of test span and fibre volume fraction on Charpy impact characteristics, Composites: Part B 44 (2013), 472-479.

[51] R. Erdem, Evaluation of electromagnetic shielding eftectiveness of multi-axial fabrics and their PES composites", Bulletin Of Materials Science, 2016 vol.39, pp.963-970.

[52] F.M.Smits, Measurement of sheet resistivities with the four-point-probe, The Bell System Technical Journal (1958).

[53] M. Hausladen, Titanium nitride thin films for sensor applications, Master of Science Thesis, University of Southern Denmark, Denmark, 2014, pp 97-100.

[54] Palmeri, M. J., Putz, K. W., Ramanathan, T., \& Brinson, L. C. (2011). Multi-scale reinforcement of CFRPs using carbon nanofibers. Composites Science and Technology, 71(2), 79-86. 